\title{
Avaliação da resistência ao fogo de paredes maciças de concreto armado
}

\author{
Evaluation of fire resistance of massive reinforced \\ concrete walls
}

\author{
Fabrício Longhi Bolina \\ Gustavo Luis Prager \\ Eduardo Rodrigues \\ Bernardo Fonseca Tutikian
}

Resumo

Fabrício Longhi Bolina Universidade do Vale do Rio dos Sinos São Leopoldo - RS - Brasil

Gustavo Luis Prager Universidade do Vale do Rio dos Sinos São Leopoldo - RS - Brasil

Eduardo Rodrigues Universidade do Vale do Rio dos Sinos São Leopoldo - RS - Brasil

Bernardo Fonseca Tutikian Universidade do Vale do Rio dos Sinos São Leopoldo - RS - Brasil

Recebido em 15/11/14 Aceito em 30/06/15

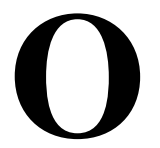

desempenho das construções está em evidência no Brasil, principalmente após a aprovação da Norma de Desempenho, a ABNT NBR 15575: 2013. Esta norma remete a necessidade dos sistemas construtivos de atender, dentre outros, a níveis mínimos de segurança contra incêndio. O intento deste artigo é estudar o potencial de aplicação na construção civil de sistemas de vedação vertical de concreto armado em termos de resistência ao fogo. Através de protótipos ensaiados em escala real (3,15 x 3,00 m) em um forno vertical normatizado, foram analisadas duas espessuras de paredes de concreto armado maciço, de 10 e $14 \mathrm{~cm}$, com um mesmo traço, observando o comportamento em termos de isolamento térmico, estanqueidade e estabilidade. Evidenciou-se que as amostras atenderam as condições aplicáveis para até 120 minutos de ensaio, com a de $14 \mathrm{~cm}$ mostrando melhores índices de isolamento térmico e estanqueidade.

Palavras-chave: Segurança contra incêndio. Desempenho. Sistemas de vedação vertical.

\section{Abstract}

Buildings' performance building is in evidence in Brazil, especially after the adoption of the Performance Standard ABNT NBR 15575: 2013. This

standard is concerned with the need of building systems to meet minimal fire safety requirements, among others. The aim of this paper is to investigate the potential application vertical sealing of reinforced concrete for fire resistance purposes by the construction industry. Through prototypes tested at full scale $(3.15 \times 3.00 \mathrm{~m})$ in a standardized vertical furnace, two wall thicknesses $(10$ and $14 \mathrm{~cm}$ ), with the same concrete mix were analysed by observing their behaviour in terms of thermal insulation, sealing and stability. The tests demonstrated that the samples met the applicable conditions for up to 120 minutes of testing, with the $14 \mathrm{~cm}$ thickness showing better rates of thermal insulation and sealing.

Keywords: Fire safety. Performance. Sealing systems. 


\section{Introdução}

O desempenho das edificações é um tema em evidência no cenário brasileiro, principalmente após a aprovação da norma de desempenho das edificações, a NBR 15575 (ABNT, 2013). Composta de seis partes, que analisam os requisitos gerais, estruturais, de pisos, de vedações, de coberturas e hidrossanitários, essa regulamentação objetiva a validação e aplicabilidade em termos de segurança, conforto, resistência e durabilidade dos materiais e sistemas construtivos frequentemente utilizados no setor. Entre tais requisitos de segurança está a resistência ao fogo dos sistemas constituintes das edificações habitacionais (BOLINA; ESTEVAM; TUTIKIAN, 2014), tais como o de vedação vertical. Segundo Buchanan e Munukutla (1991), quando ocorre um incêndio em um edifício, paredes são necessárias para limitar a propagação do fogo aos cômodos vizinhos, mantendo a integridade e a segurança da edificação durante algum tempo.

No que tange à resistência ao fogo, destaca Silva (2013) que esta é a propriedade de um elemento resistir à ação do fogo, mantendo sua integridade, segurança estrutural, estanqueidade e isolamento quando submetido a esse fenômeno. Geralmente essa resistência é medida segundo o tempo que o elemento suporta a ação do fogo produzido durante um incêndio. No Brasil, em termos de regulamentação técnica, esse tempo é definido pela NBR 14432 (ABNT, 2001a) - Exigências de resistência ao fogo de elementos construtivos de edificações. Para cada elemento construtivo a norma estabelece uma resistência requerida mínima ao fogo, o tempo requerido de resistência ao fogo (TRRF), em função da altura, da ocupação e do uso de uma edificação.

A Instrução Técnica n. 8 do Corpo de Bombeiros da Polícia Militar do Estado de São Paulo (CBPMESP), a IT08:2011 (SÃO PAULO, 2011), utilizada em 16 estados do Brasil até 13 de fevereiro de 2015, especifica que o TRRF, em essência, visa prevenir o colapso de uma edificação em situação de incêndio por determinado período, propiciando a saída segura dos ocupantes, limitando a propagação do fogo para compartimentos adjacentes e preservando condições mínimas para o trabalho do Corpo de Bombeiros. A perda patrimonial e a proteção ao meio ambiente surgem também como objetivos almejados - de caráter secundário - quando se estabelece uma resistência ao fogo para as edificações (WANG et al., 2013). Assim, entre os sistemas que se necessita garantir tais requisitos de resistência ao fogo está, além do estrutural, o de vedação vertical, necessário para possibilitar a compartimentação adequada dos ambientes, evitando ou minimizando a propagação do incêndio e facilitando a evacuação dos usuários com segurança.

Conceitua-se a compartimentação como uma medida de proteção passiva, constituída de elementos de construção resistentes ao fogo, destinados a evitar ou minimizar sua propagação, bem como do calor e gases, interna ou externamente ao edifício. Desde as últimas catástrofes nacionais, como o incêndio da Boate Kiss, as leis nacionais de segurança contra incêndio foram reformuladas, as exigências para aprovação de projetos foram estreitadas, e, concomitante com as exigências de desempenho das construções, as normas passaram a ser atualizadas e os sistemas construtivos revistos. Passou-se a ter a necessidade de validar os sistemas construtivos em termos de resistência ao fogo para promover de fato sua aplicabilidade na construção civil. A Lei Complementar n. 14.376, de 26 de dezembro de 2013, do Rio Grande do Sul (RIO..., 2013), por exemplo, estabelece como obrigatório o uso de compartimentação vertical e horizontal para edificações residenciais com mais de $12 \mathrm{~m}$ de altura, ou conforme as atividades (ocupações)

Segundo a NBR 10636 (ABNT, 1989) - Paredes divisórias sem função estrutural: determinação da resistência ao fogo, a resistência ao fogo de paredes e divisórias sem função estrutural é satisfeita quando for capaz de garantir a estabilidade, estanqueidade e isolamento térmico. A IT08:2011 (SÃO PAULO, 2011) estabelece que os elementos de compartimentação devem apresentar o mesmo TRRF da estrutura. Essa mesma instrução técnica elucida que as paredes divisórias entre unidades autônomas e entre unidades e áreas comuns devem apresentar um TRRF suficiente para oferecer segurança durante a evacuação dos usuários.

No entanto, a IT08:2011 (SÃO PAULO, 2001) dispõe recomendações de construção para os sistemas de alvenaria e de chapas para gesso acartonado. Para paredes de concreto armado, a Instrução Técnica valida as espessuras de $11,5 \mathrm{~cm}$ e $16 \mathrm{~cm}$ para TRRF de $60 \mathrm{~min}$ e $180 \mathrm{~min}$ respectivamente. Porém, para espessuras distintas não há referência no sistema normativo brasileiro, como ocorre no sistema europeu, através da BS EN 1992-1-2 (EUROPEAN..., 2004), que apresenta validações das espessuras de 6, 8, 10, 12, 15 e $17,5 \mathrm{~cm}$ para TRRF de $30,60,90,120,180$ e $240 \mathrm{~min}$ respectivamente.

292 Bolina, F. L.; Prager, G. L.; Rodrigues, E.; Tutikian, B. F. 
Por outro lado, destacam Mehta e Monteiro (2014) que muitos fatores controlam a resposta do concreto ao fogo, sendo difícil precisar e antever o efetivo comportamento dos elementos constituídos por esse material. Ainda destacam os autores que a composição do concreto é importante, uma vez que tanto a pasta quanto o agregado se decompõem de forma distinta quando submetidos ao calor. A própria permeabilidade do concreto remetida pela relação água/cimento e a resistência à compressão, a geometria do elemento e a taxa de aumento de temperatura são importantes, pois governam o comportamento desse material nessa circunstância.

Para suprir essa lacuna do sistema normativo brasileiro, bem como ensaiar elementos com os materiais de construção locais e analisar o comportamento de determinado traço de concreto, o intento deste trabalho é avaliar o comportamento de paredes de concreto armado maciço, com espessuras de $10 \mathrm{~cm} \mathrm{e} 14 \mathrm{~cm}$, analisando a segurança contra incêndio. No Brasil, sistemas constituídos de parede de concreto armado maciço vêm sendo cada vez mais utilizados, desde edificações mais baixas, até 5 pavimentos, com espessuras de $10 \mathrm{~cm}$, até edificações mais altas com maior padrão de acabamento, com espessuras de até $14 \mathrm{~cm}$.

Para cumprir com o propósito de analisar o desempenho das paredes de concreto em situação de incêndio, o trabalho fundamentou-se na moldagem e análise da resistência ao fogo de duas paredes maciças de concreto armado de mesmo traço e com espessuras distintas. Obedecendo ao prescrito pela NBR 10636 (ABNT, 1989), as paredes foram ensaiadas em escala real, com dimensões de 3,15x3,00 m, através de um forno vertical normatizado e calibrado. O estudo foi estruturado em quatro partes: $\left(1^{\circ}\right)$ introdução; $\left(2^{\circ}\right)$ materiais e métodos; $\left(3^{\circ}\right)$ resultados e discussão; e $\left(4^{\circ}\right)$ conclusão.

\section{Materiais e métodos}

\section{Materiais}

O concreto empregado foi usinado, e para as formas foi utilizada madeira. A Tabela 1 mostra as propriedades do concreto que foi empregado para a confecção das amostras.
O traço (em massa) empregado para a produção do concreto foi $1: 2,9: 3,6$. As características dos materiais estão descritas abaixo:

(a) cimento Portland CPV;

(b) agregado miúdo de quartzo de rio, com diâmetro máximo de 4,8 $\mathrm{mm}$, módulo de finura 2,65 e massa específica de $2,61 \mathrm{~g} / \mathrm{cm}^{3}$;

(c) agregado graúdo basáltico, com diâmetro máximo de $19 \mathrm{~mm}$, módulo de finura 6,82 e massa específica de $2,74 \mathrm{~g} / \mathrm{cm}^{3}$; e

(d) água potável oriunda do sistema de abastecimento da cidade de São Leopoldo, RS, Brasil.

Segundo Oliveira (2013), para concretos convencionais, a variação da resistência à compressão possui pouca influência em seu comportamento ao fogo. Ainda, o tipo de agregado e de cimento não acarreta alterações durante o ensaio, conforme evidenciam Santos e Rodrigues (2013). Por isso, os critérios brasileiros estipulados pela NBR 15200 (ABNT, 2012) para projeto de estruturas de concreto armado em situação de incêndio não são influenciados pela resistência à compressão do concreto e seus constituintes.

As paredes moldadas foram curadas em temperatura ambiente, com aspersão contínua de água por 7 dias. O aço empregado foi o CA50, com tensão característica de escoamento de 500 $\mathrm{MPa}$, com barras de diâmetro nominal de 12,5 $\mathrm{mm}$, espaçadas a cada $15 \mathrm{~cm}$. Foi usada uma tela no painel, totalizando a taxa de aço de $80 \mathrm{~kg} / \mathrm{m}^{3}$.

\section{Amostragem e moldagem das amostras}

As paredes foram desenvolvidas com área superficial e dosagens idênticas, variando a espessura, uma com $10 \mathrm{~cm}$ (parede 1) e outra com $14 \mathrm{~cm}$ (parede 2). Os dois protótipos ensaiados são maciços, sem aberturas, com $3,15 \times 3,00 \mathrm{~m}$. A superfície exposta a altas temperaturas é de 2,50x2,00 m, utilizando o restante das paredes para isolamento do forno. Para que o sistema fosse ensaiado, ele foi montado sobre um carro móvel, de forma a facilitar a aproximação dos referidos corpos de prova junto ao forno do ensaio.

Tabela 1 - Propriedades do concreto para cada uma das paredes ensaiadas

\begin{tabular}{c|c|c|c}
\hline \multirow{2}{*}{ Parede n $^{\mathbf{o}}$} & \multicolumn{3}{|c}{ Propriedades do concreto } \\
\cline { 2 - 4 } & fck (MPa) & Rel. a/c & Cimento \\
\hline 1 & 25 & 0,60 & CPIV \\
2 & 25 & 0,60 & CPIV \\
\hline
\end{tabular}


As paredes foram moldadas na horizontal, seguindo o procedimento da NBR 14931 (ABNT, 2004), em formas de madeira, e, após a cura de 28 dias, foram instaladas verticalmente junto ao forno para proceder aos ensaios.

\section{Forno e execução do ensaio}

O forno admitido no ensaio é do tipo vertical, com aquecimento realizado através de quatro queimadores alimentados a gás com controle dos diferenciais de pressão conforme a área examinada. Os queimadores são instalados junto às paredes laterais verticais do forno (dois por parede) e estão programados para produzir aumento de temperatura em seu interior, segundo a curva de aquecimento estabelecida na NBR 10636 (ABNT, 1989), idêntica à ISO 834-1 (INTERNATIONAL..., 1999), a qual especifica uma variação de temperatura interna conforme a Equação (1).

$\mathrm{T}-\mathrm{T}_{\mathrm{o}}=345 \cdot \log \left(8 \mathrm{t}^{\prime}+1\right)$

Eq. 1

Onde:

$\mathrm{T}$ : temperatura do forno no tempo $\mathrm{T}$, em ${ }^{\circ} \mathrm{C}$;

$\mathrm{T}_{\mathrm{o}}$ : temperatura inicial do forno, em ${ }^{\circ} \mathrm{C}$, sendo 10

${ }^{\circ} \mathrm{C} \leq \mathrm{T}_{\mathrm{o}}<40^{\circ} \mathrm{C}$; e

t': tempo do ensaio, em minutos.

incêndio-padrão, estabelecida a partir do fenômeno que causa a elevação abrupta das temperaturas em um compartimento incendiado, a ignição súbita generalizada (flashover). Essa curva, com elevação constante de temperatura, é também uma simplificação bem aceita no meio técnico para a realização de dimensionamento, ensaios e análises, já que a curva real de incêndio é influenciada por uma série de fatores (área das aberturas, carga de incêndio, entre outros), sendo de difícil caracterização (CADORIN, 2003). Estabelece-se que a peça jamais será submetida a um incêndio de intensidade semelhante na qual a curva de ensaio submete o material (AMERICAN..., 2007; BRITISH..., 2004a; INTERNATIONAL..., 1999; AUSTRALIAN..., 2005; JAPANESE..., 1994).

A evolução de temperatura é continuamente monitorada durante o ensaio. Dois termopares instalados dentro do forno permitem a análise da temperatura interna dele. Caso ocorra desvio da evolução da temperatura interna do forno além dos limites fixados pela NBR 10636 (ABNT, 1989), uma correção da intensidade da chama produzida pelos queimadores é realizada. Ainda há a possibilidade do uso de termoplacas para a calibração da temperatura interna do forno, mas, apesar da boa precisão, possuem custo elevado e não são facilmente encontradas no mercado.

Durante o ensaio, a temperatura da face interna da amostra deve ser a média aritmética das temperaturas medidas por termopares arranjados simetricamente dentro do forno, em número igual a 5 , sendo 1 para cada $1,5 \mathrm{~m}^{2}$ de superfície exposta do corpo de prova. As temperaturas são medidas com precisão de $\pm 1,5 \%$, sendo continuamente registradas durante o ensaio. A configuração do forno é apresentada nas Figuras 1 e 2.

O método de ensaio utilizado foi o prescrito pela NBR 10636 (ABNT, 1989). O objetivo do ensaio é verificar as características de estabilidade estrutural, estanqueidade e isolamento térmico de cada parede, analisando sua potencialidade de emprego como elemento de compartimentação vertical de edificações.

\section{Figura 1 - Detalhe do forno com os queimadores acesos}

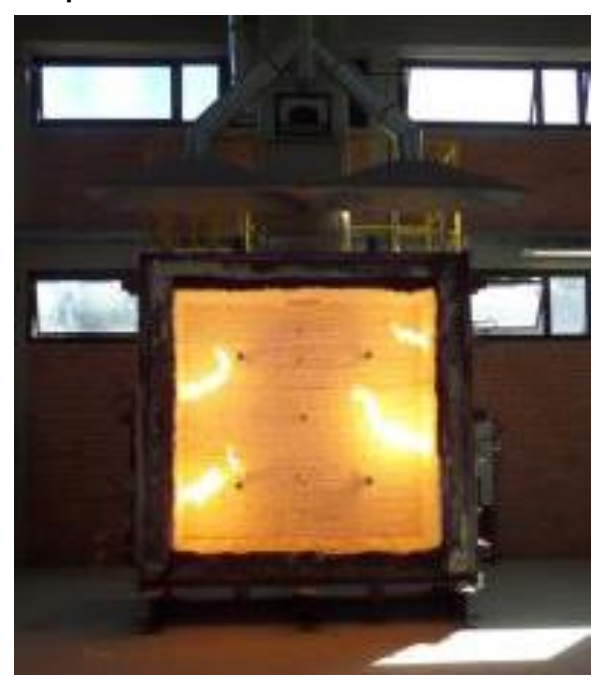

294 Bolina, F. L.; Prager, G. L.; Rodrigues, E.; Tutikian, B. F. 
Figura 2 - Detalhe da disposição dos termopares internos do forno

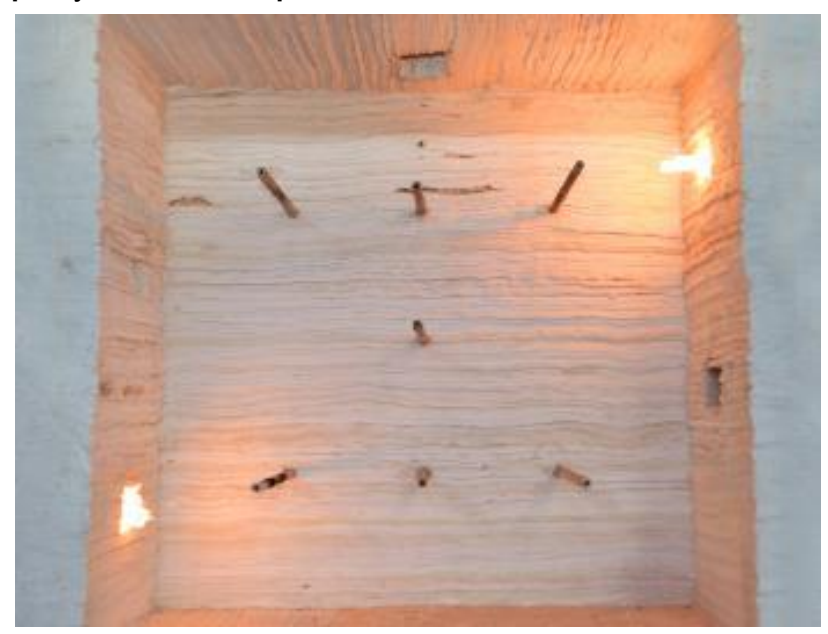

\section{Parâmetros avaliados}

Os parâmetros avaliados neste estudo foram o isolamento térmico, a estanqueidade e a estabilidade das paredes, o que compõe a resistência ao fogo. $\mathrm{O}$ acompanhamento do isolamento térmico é feito por termopares, correlacionando as temperaturas internas $\mathrm{e}$ externas com o tempo transcorrido de ensaio. Segundo os preceitos da NBR 10636 (ABNT, 1989), as variações de temperaturas máximas registradas não podem superar $180{ }^{\circ} \mathrm{C}$ em cada termopar ou $140{ }^{\circ} \mathrm{C}$ sobre a média aritmética destes. Já a E 119 (AMERICAN..., 2014) estabelece como $250{ }^{\circ} \mathrm{F}\left(139{ }^{\circ} \mathrm{C}\right)$ a variação máxima da temperatura média dos termopares em relação à temperatura média inicial destes. A norma australiana AS 1530 (AUSTRALIAN..., 2005) limita a temperatura média dos termopares em $140{ }^{\circ} \mathrm{K}\left(133{ }^{\circ} \mathrm{C}\right)$. Todo o procedimento de coleta das temperaturas foi filmado com câmara termográfica, acompanhando o desenvolvimento do calor externo da amostra no tempo.

A estanqueidade das amostras deve ser observada por intermédio de um chumaço de algodão, que, posicionado por $10 \mathrm{~s}$ sobre as eventuais fissuras, com $1 \mathrm{~cm}$ a $3 \mathrm{~cm}$ de distância, não inflame, obedecendo às prescrições da NBR 5628 (ABNT, 2001b). As fissuras deflagradas, caso não provoquem a inflamação do chumaço de algodão, não serão registradas e locadas, uma vez que elas não comprometem a estanqueidade. A NBR 10636 (ABNT, 1989) explica que, para analisar a estanqueidade do elemento estrutural submetido ao fogo, devem ser avaliadas as fissuras ou outras aberturas que surjam no ato do ensaio. Tal como a E 119 (AMERICAN..., 2014) e a AS 1530 (AUSTRALIAN..., 2005), a norma brasileira classifica como estanques todas as paredes que, ao propagar fissuração, não provoquem a inflamação de um chumaço de algodão.

Por fim, foram realizadas as medições da deformação e visualizado se ocorreu o colapso durante os ensaios, caracterizando a estabilidade. Esta análise se torna importante para avaliar a integridade do elemento quando submetido a altas temperaturas, observando se ele produzirá deformação excessiva a ponto de colapsar ou promover comprometimento da segurança dos usuários. Entretanto, além de uma estabilidade própria, o sistema deve ser estável quando lhe for arremessado qualquer material ou até mesmo diante do impacto de uma pessoa durante o sinistro, o que foi avaliado através do choque mecânico da esfera $3 \mathrm{~min}$ antes do término do ensaio. Segundo a NBR 10636 (ABNT, 1989), a deformação do sistema não deve ser excessiva, no entanto não é especificada a magnitude aceitável de tal deformação, cabendo ao profissional identificar a condição-limite. A E 119 (AMERICAN..., 2014) também não impõe restrições à deformação, destacando como exigência apenas a capacidade do sistema de ficar estável durante o período de teste. Segundo a NBR 10636 (ABNT, 1989), a estabilidade deve ser verificada através de impactos que promovam solicitações horizontais ao sistema de vedação durante o ensaio. Tal circunstância é verificada através da aplicação de um choque mecânico, que consiste em submeter a superfície não exposta ao fogo a um impacto de uma esfera de aço em movimento pendular com massa entre $15 \mathrm{~kg}$ e 25 $\mathrm{kg}$, de forma a ocasionar um impacto com energia correspondente a $20 \mathrm{~J}$. Os impactos devem ser realizados em três pontos distintos da parede, alinhados horizontalmente, a $1,40 \mathrm{~m}$ da base do corpo de prova. 


\section{Instrumentação do ensaio}

A listagem dos equipamentos empregados nos ensaios é apresentada na Tabela 2.

$\mathrm{Na}$ parte interna, junto ao forno, cinco termopares fixos medem a temperatura na superfície exposta ao fogo do sistema. $\mathrm{Na}$ parte externa cinco termopares são acoplados junto à superfície destes. Os termopares internos são do tipo $\mathrm{K}$, com diâmetro de $4 \mathrm{~mm}$, e os externos são do tipo K, com diâmetro de $2 \mathrm{~mm}$. A numeração dos termopares externos adotados no estudo está elucidada na Figura 3. Os termopares 6, 7, 9 e 10 estão instalados a $1 \mathrm{~m}$ da borda da parede, e o termopar 8, no centro da amostra. Os termopares externos coincidem com a posição dos termopares internos.

\section{Critérios para interrupção do ensaio ou de falha}

Convencionou-se analisar o comportamento das amostras até o tempo de $120 \mathrm{~min}$, por ser o tempo máximo requerido pela NBR 14432 (ABNT, 2001a) para o cumprimento de resistência ao fogo de elementos construtivos. Assim, atendeu-se à maioria das edificações habitacionais executadas no território brasileiro. Além disso, o ensaio seria interrompido caso houvesse qualquer perda de estanqueidade e isolação térmica do sistema, bem como deformações ou colapso que comprometessem a segurança dos operadores do forno.

\section{Resultados e discussão}

\section{Aspectos gerais}

$\mathrm{O}$ ensaio da parede 1 , com $10 \mathrm{~cm}$ de espessura, iniciou-se com temperatura (To) de $25,62{ }^{\circ} \mathrm{C}$, atingindo $117,2^{\circ} \mathrm{C}$, no final do ensaio. Já a parede 2, com $14 \mathrm{~cm}$ de espessura, iniciou com a temperatura (To) de $20,76{ }^{\circ} \mathrm{C}$ e finalizou com $96,22^{\circ} \mathrm{C}$. As manifestações observadas durante a elaboração dos ensaios estão descritas na Tabela 3.

Para a parede de $10 \mathrm{~cm}$ e a parede de $14 \mathrm{~cm}$, um início de liberação de água pode ser observado aos 17 min e 26 min respectivamente. Conforme Robert, Colina e Debicki (2014), em temperaturas inferiores a $100{ }^{\circ} \mathrm{C}$ há perda de água dos macroporos. Acima de $100{ }^{\circ} \mathrm{C}$ inicia-se a perda de água capilar, da água de poros mais finos, da água retida por adsorção e da água que representa ligações fracas com os hidratos de cimento. A quantidade de água perdida até $500{ }^{\circ} \mathrm{C}$, explicam os autores, representa de $2 \%$ a $4 \%$ em massa (em torno de $50 \mathrm{~L}$ a $100 \mathrm{~L}$ de água por metro cúbico de concreto). Assim, tal fenômeno pode ser deduzido na própria temperatura interna do forno, remetida na Tabela 4, que em um tempo de 10 min já expõe os elementos a $600{ }^{\circ} \mathrm{C}$. Pelo fato de a segunda parede possuir volume maior, é justificável a perda de água póstuma quando comparada com a primeira parede.

Tabela 2 - Listagem dos equipamentos empregados na realização dos ensaios

\begin{tabular}{c|c|c}
\hline Descrição & Modelo & Calibração \\
\hline Forno vertical & GFT 03276 FG & $\begin{array}{c}\text { Resolução 0,01 }{ }^{\circ} \mathrm{C} \\
\text { Capacidade térmica } 1.200{ }^{\circ} \mathrm{C}\end{array}$ \\
\hline Câmera termográfica & A325 & FLIR \\
\hline Trena a laser & GLM 80 Professional & Bosch \\
\hline
\end{tabular}

Figura 3 - Numeração dos termopares dispostos junto à face externa das paredes

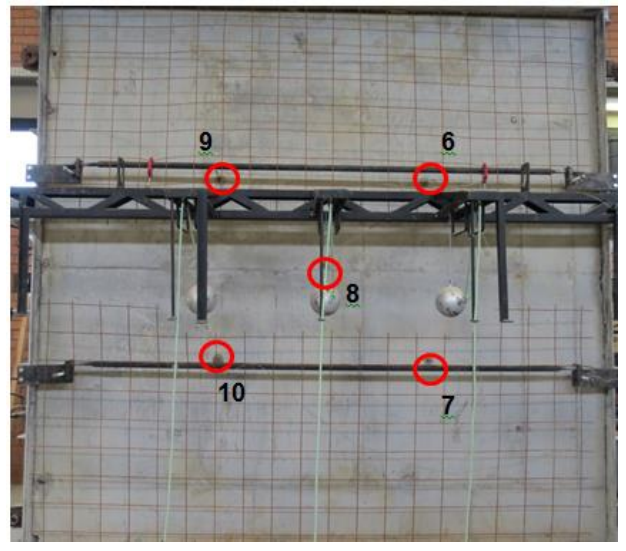

296 Bolina, F. L.; Prager, G. L.; Rodrigues, E.; Tutikian, B. F. 
Tabela 3 - Desenvolvimento do ensaio de resistência ao fogo das paredes 1 e 2

\begin{tabular}{|c|c|c|c|}
\hline \multicolumn{2}{|r|}{ PAREDE $1-10 \mathrm{~cm}$} & \multicolumn{2}{|r|}{ PAREDE $2-14 \mathrm{~cm}$} \\
\hline Tempo & Descrição & Tempo & Descrição \\
\hline $0: 00$ & Início do ensaio & $0: 00$ & Início do ensaio \\
\hline $14 \min$ & $\begin{array}{l}\text { Amostra começa a liberar água da } \\
\text { composição }\end{array}$ & $13 \mathrm{~min}$ & $\begin{array}{l}\text { Foco de calor na parte central da } \\
\text { amostra }\end{array}$ \\
\hline $17 \mathrm{~min}$ & $\begin{array}{l}\text { Inicia-se um acréscimo de calor no } \\
\text { ponto onde aconteceu a liberação } \\
\text { de água }\end{array}$ & $14 \min$ & $\begin{array}{l}\text { Amostra começa a liberar água da } \\
\text { composição }\end{array}$ \\
\hline $20 \mathrm{~min}$ & Formação da primeira fissura & $26 \min$ & $\begin{array}{l}\text { Inicia-se um acréscimo de calor no } \\
\text { ponto onde aconteceu a liberação de } \\
\text { água }\end{array}$ \\
\hline $35 \mathrm{~min}$ & $\begin{array}{l}\text { Acréscimo de calor generalizado na } \\
\text { amostra }\end{array}$ & $28 \mathrm{~min}$ & Formação da primeira fissura \\
\hline $46 \mathrm{~min}$ & $\begin{array}{l}\text { Amostra continua a liberar água da } \\
\text { composição }\end{array}$ & $32 \mathrm{~min}$ & $\begin{array}{l}\text { Amostra continua a liberar água da } \\
\text { composição e gases pela fissura } \\
\text { formada }\end{array}$ \\
\hline $66 \min$ & $\begin{array}{l}\text { Pontos generalizados de irradiação } \\
\text { de calor }\end{array}$ & $56 \mathrm{~min}$ & Não há mais liberação de água \\
\hline $81 \mathrm{~min}$ & Não há mais liberação de água & 117 min & $\begin{array}{l}\text { Realização de ensaio de choque } \\
\text { mecânico para } 120 \text { min }\end{array}$ \\
\hline $117 \mathrm{~min}$ & $\begin{array}{l}\text { Realização de ensaio de choque } \\
\text { mecânico para } 120 \mathrm{~min}\end{array}$ & $120 \mathrm{~min}$ & Término do ensaio \\
\hline $120 \mathrm{~min}$ & Término do ensaio & & \\
\hline
\end{tabular}

A formação das primeiras fissuras, identificadas aos $20 \mathrm{~min}$ para a parede de $10 \mathrm{~cm}$ e aos $28 \mathrm{~min}$ para a parede de $14 \mathrm{~cm}$, observadas após o início da perda de água, é justificável pela própria variação da massa volumétrica, motivada pela variação da porosidade e da perda de água. Novamente as primeiras fissuras na parede menos espessa é justificada pelo próprio volume desta, remetendo à temperatura média superior dela quando comparada com a segunda parede, mais espessa.

Observa-se que a parede de $14 \mathrm{~cm}$ mostra ter melhor comportamento do que a de $10 \mathrm{~cm}$, com um retardo de tempo para todas as consequências ocorridas ao longo do ensaio. Por exemplo, o tempo em que as amostras finalizam a liberação de água, quando perdem toda a umidade livre e o concreto passa a perder a água adsorvida, foi de 81 min para a parede de $10 \mathrm{~cm}$ e de 56 min para a de $14 \mathrm{~cm}$ de espessura, uma diminuição de $25 \mathrm{~min}$.

\section{Avaliação do isolamento térmico}

$\mathrm{O}$ isolamento térmico das paredes foi verificado com a análise da temperatura na face das amostras não exposta ao fogo, ou seja, a temperatura do ambiente adjacente ao ambiente em que transcorre o incêndio. As Figuras 4 e 5 apresentam respectivamente os gráficos com os valores de temperatura registrados pelos termopares fixados nas paredes 1 e 2 .

A temperatura máxima medida na parede 1 , de 10 $\mathrm{cm}$, foi de $117,2^{\circ} \mathrm{C}$, enquanto na parede 2 , de 14 $\mathrm{cm}$, foi de $96,4^{\circ} \mathrm{C}$, obedecendo aos requisitos de isolamento normatizados da NBR 10636 (ABNT, 1989), E 119 (AMERICAN..., 2014) e AS 1530 (AUSTRALIAN..., 2005). A Tabela 4 apresenta as temperaturas médias do forno (curva-padrão) da face não exposta ao fogo no decorrer do ensaio de cada parede. Essas medidas de temperatura foram realizadas através de termopares.

Ainda foi realizada uma análise das temperaturas com o auxílio da termografia, conforme consta nas Figuras 6 a 9, mostrando a parede 1 , de $10 \mathrm{~cm} \mathrm{de}$ espessura, e a parede 2 , com $14 \mathrm{~cm}$ de espessura, nos tempos de $30 \mathrm{~min}$ e $110 \mathrm{~min}$ aproximadamente. 
Figura 4 - Temperatura nos termopares sobre a superfície externa da parede 1 - $10 \mathrm{~cm}$

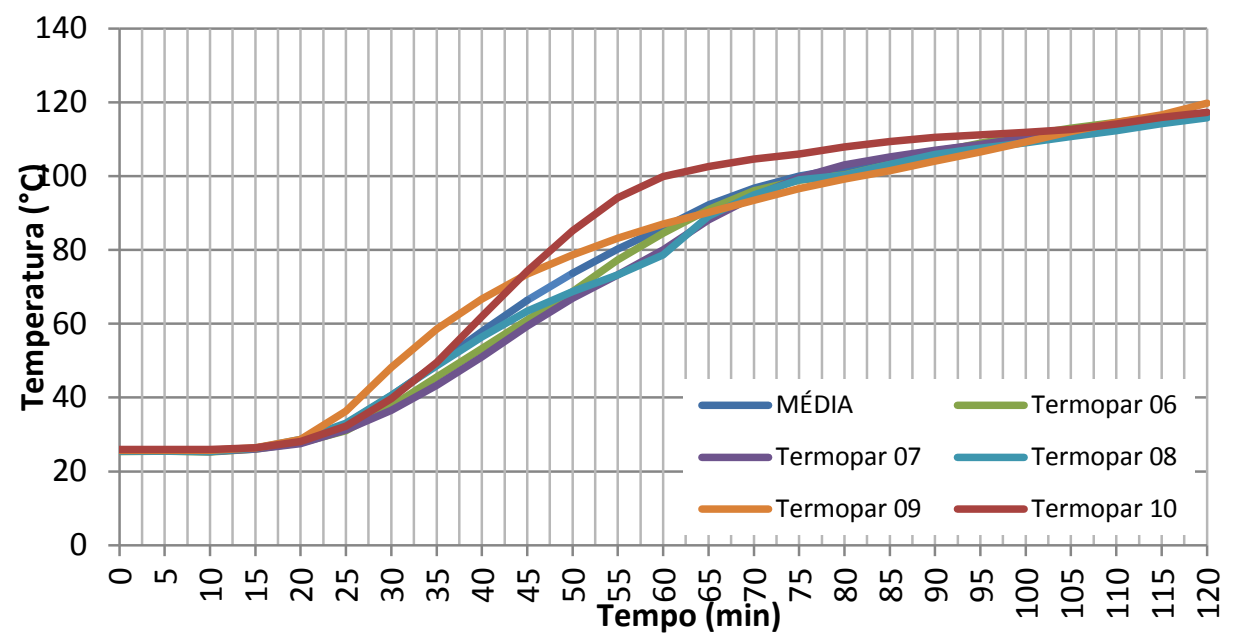

Figura 5 - Temperatura nos termopares sobre a superfície externa da parede 2 - $14 \mathrm{~cm}$

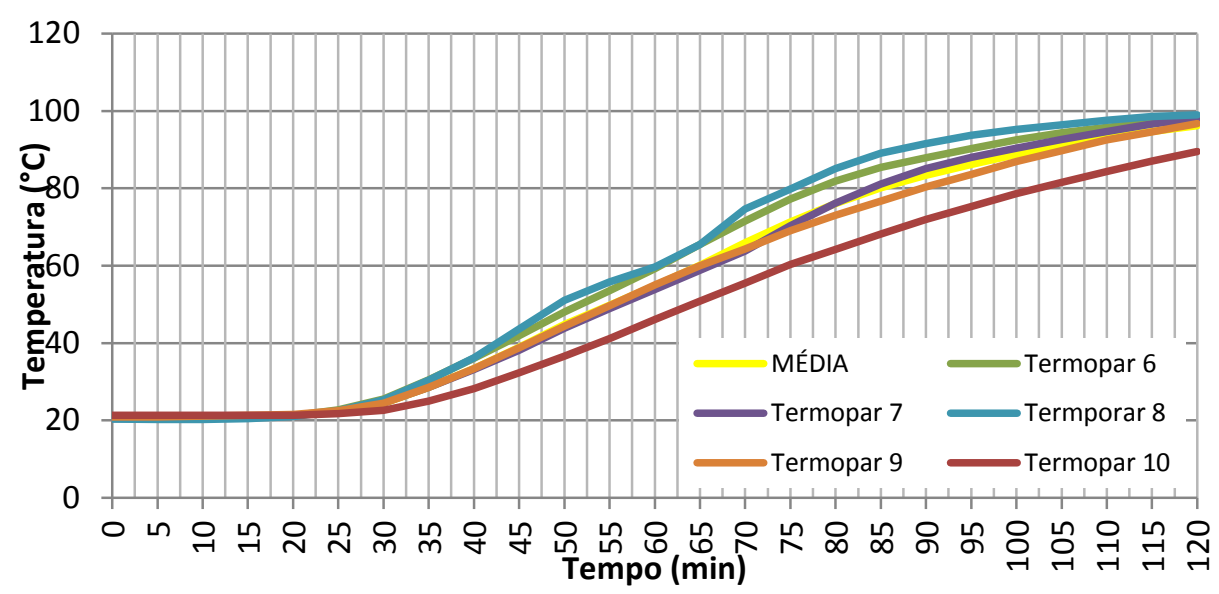

Com base na Tabela 4 e nas Figuras 6 a 9, observase que em todas as situações a parede de concreto de $14 \mathrm{~cm}$ de espessura apresentou temperatura da face externa sempre inferior à temperatura da face externa da parede de concreto de $10 \mathrm{~cm}$ de espessura. Essa diferença de temperatura chega a ser de $32,1^{\circ} \mathrm{C}$, conforme evidenciado no tempo transcorrido de $65 \mathrm{~min}$ de ensaio. Isso mostra a influência positiva do aumento da espessura das paredes em termos de isolamento térmico. 
Tabela 4 - Temperatura média dos termopares nas paredes 1 e 2

\begin{tabular}{|c|c|c|c|c|c|}
\hline \multirow[b]{2}{*}{$\begin{array}{c}\text { Tempo } \\
(\mathrm{min})\end{array}$} & \multicolumn{2}{|c|}{ PAREDE $1-10 \mathrm{~cm}$} & \multicolumn{2}{|c|}{ PAREDE $2-14 \mathrm{~cm}$} & \multirow[b]{2}{*}{$\begin{array}{c}\text { Diferença de } \\
\text { temperatura entre as } \\
\text { paredes } 1 \text { e } 2\left({ }^{\circ} \mathrm{C}\right)\end{array}$} \\
\hline & $\begin{array}{l}\text { Curva- } \\
\text { padrão } \mathrm{T}^{\prime}- \\
\text { To }\left({ }^{\circ} \mathrm{C}\right) \\
\end{array}$ & $\begin{array}{c}\text { Temperatura média da } \\
\text { face não exposta ao } \\
\text { fogo }\left({ }^{\circ} \mathrm{C}\right)\end{array}$ & $\begin{array}{l}\text { Curva- } \\
\text { padrão } \mathrm{T}^{\prime}- \\
\text { To }\left({ }^{\circ} \mathrm{C}\right) \\
\end{array}$ & $\begin{array}{l}\text { Temperatura média } \\
\text { da face não exposta } \\
\text { ao fogo }\left({ }^{\circ} \mathrm{C}\right)\end{array}$ & \\
\hline 5 & 556 & 25,6 & 556 & 20,7 & 4,9 \\
\hline 10 & 659 & 25,5 & 659 & 20,8 & 4,7 \\
\hline 15 & 718 & 26,3 & 718 & 20,9 & 5,4 \\
\hline 20 & 821 & 28,2 & 821 & 21,2 & 7,0 \\
\hline 25 & 865 & 32,8 & 865 & 22,4 & 10,4 \\
\hline 30 & 898 & 40,5 & 898 & 24,5 & 16,0 \\
\hline 35 & 925 & 49,1 & 925 & 28,6 & 20,5 \\
\hline 40 & 948 & 57,9 & 948 & 33,4 & 24,5 \\
\hline 45 & 968 & 66,3 & 968 & 38,9 & 27,4 \\
\hline 50 & 986 & 73,6 & 986 & 44,8 & 28,8 \\
\hline 55 & 1002 & 80,2 & 1002 & 49,8 & 30,4 \\
\hline 60 & 1016 & 86,0 & 1016 & 54,8 & 31,2 \\
\hline 65 & 1029 & 92,2 & 1029 & 60,1 & 32,1 \\
\hline 70 & 1041 & 96,7 & 1041 & 65,9 & 30,8 \\
\hline 75 & 1052 & 100,0 & 1052 & 71,3 & 28,7 \\
\hline 80 & 1062 & 102,1 & 1062 & 76,1 & 26,0 \\
\hline 85 & 1077 & 104,5 & 1077 & 80,1 & 24,4 \\
\hline 90 & 1081 & 106,7 & 1081 & 83,4 & 23,3 \\
\hline 95 & 1090 & 108,6 & 1090 & 86,2 & 22,4 \\
\hline 100 & 1098 & 110,3 & 1098 & 88,7 & 21,6 \\
\hline 105 & 1106 & 112,1 & 1106 & 90,9 & 21,2 \\
\hline 110 & 1113 & 113,8 & 1113 & 93,0 & 20,8 \\
\hline 115 & 1120 & 115,6 & 1120 & 94,7 & 20,9 \\
\hline 120 & 1126 & 117,2 & 1126 & 96,2 & 21,0 \\
\hline
\end{tabular}

Figura 6 - Campo de temperatura da parede $1(10 \mathrm{~cm})$ no tempo de $30 \mathrm{~min}$

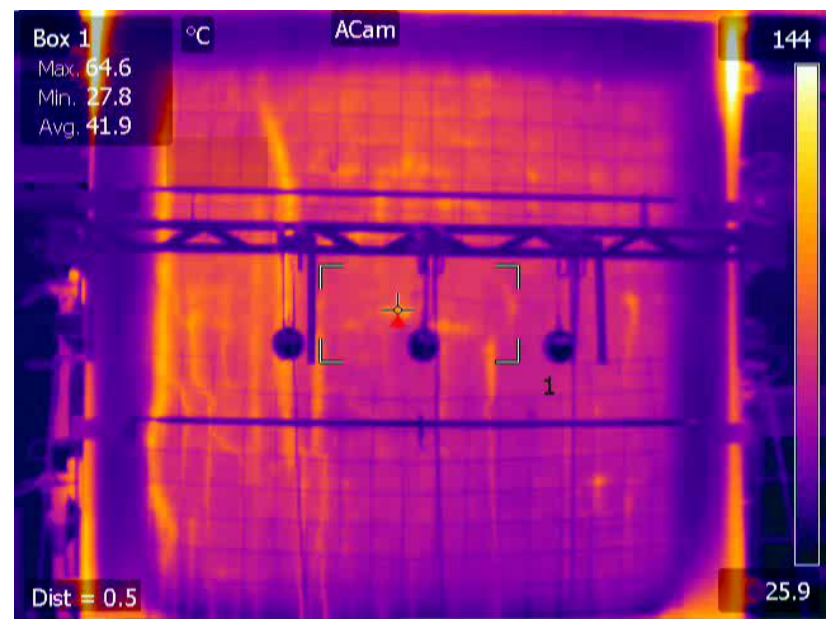


Figura 7 - Campo de temperatura da parede $1(10 \mathrm{~cm})$ no tempo de $110 \mathrm{~min}$

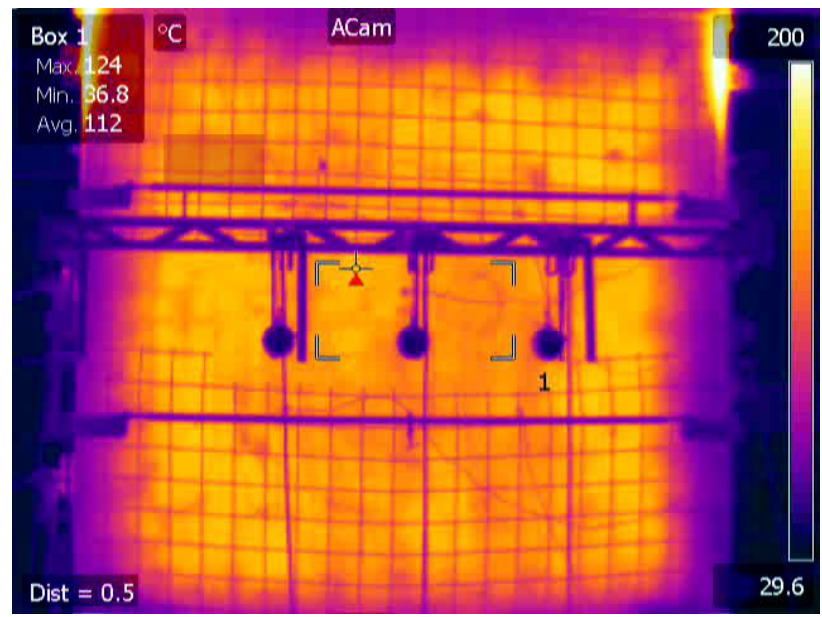

Figura 8 - Campo de temperatura da parede $2(14 \mathrm{~cm})$ no tempo de $33 \mathrm{~min}$

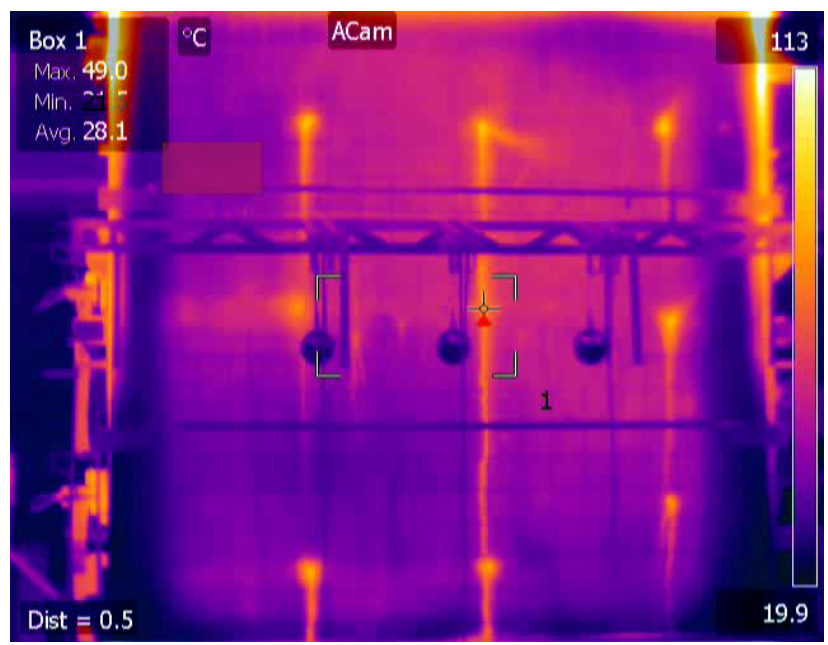

Figura 9 - Campo de temperatura da parede $2(14 \mathrm{~cm})$ no tempo de $108 \mathrm{~min}$

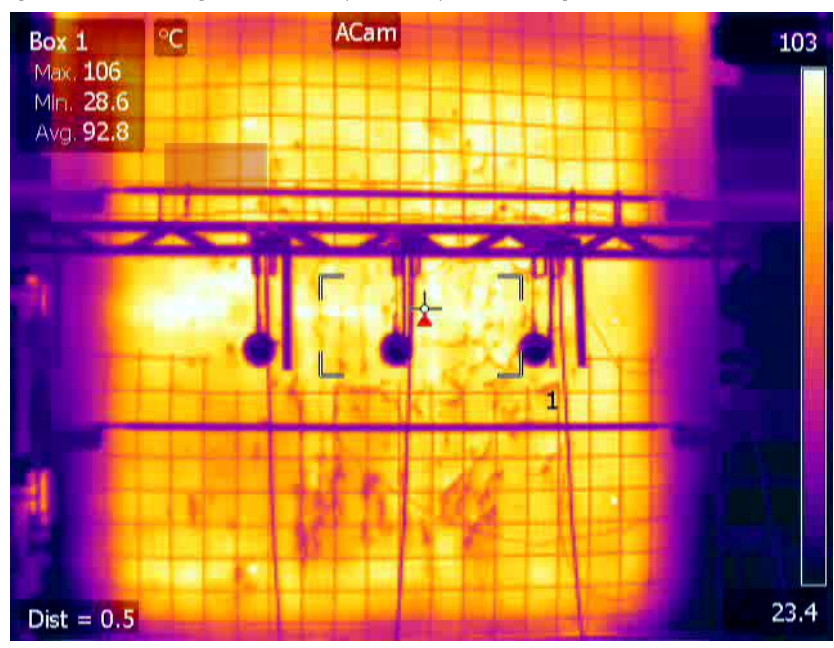

300 Bolina, F. L.; Prager, G. L.; Rodrigues, E.; Tutikian, B. F. 


\section{Avaliação da estanqueidade}

Na Figura 10 é mostrada a análise de uma fissura formada durante o período de ensaio da parede 1 . A Figura 11 mostra o operador do ensaio aproximando o chumaço de algodão na fissura formada durante o ensaio da parede 2. Observa-se que em ambos os casos não há inflamação do chumaço de algodão.

Portanto, não se observou nas duas paredes a inflamação generalizada do chumaço de algodão. Ambas as paredes apresentaram microfissuras no desenvolver do ensaio, porém estas não foram suficientes para proporcionar a passagem de gases inflamáveis para a face oposta à face de aplicação do fogo. Portanto, essas paredes seguiram o estipulado no fib Bulletin no 46 (FÉDÉRATION..., 2008). Dessa forma, é possível afirmar que o ambiente adjacente àquele em que o incêndio se deflagra está sendo preservado, não alimentando o incêndio através de uma inflamação generalizada do ambiente por gases quentes.

\section{Avaliação da estabilidade}

$\mathrm{Na}$ Tabela 5 se evidencia o deslocamento lateral sofrido pela parede 1 durante o ensaio; já na Tabela 6 se evidencia o deslocamento lateral sofrido pela parede 2, ambos medidos externamente ao forno.

Figura 10 - Avaliação da estanqueidade de uma fissura formada na parede $1(10 \mathrm{~cm})$

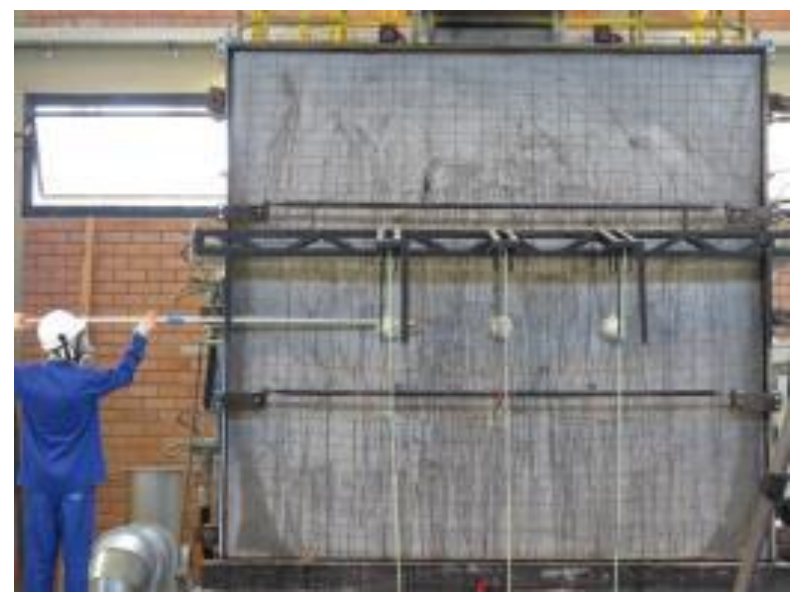

Figura 11 - Avaliação da estanqueidade de uma fissura formada na parede $2(14 \mathrm{~cm})$

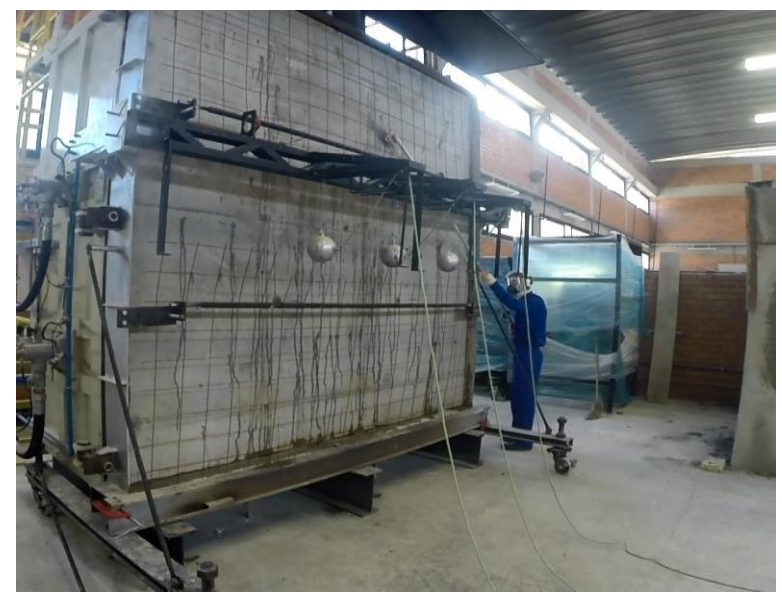


Tabela 5 - Desenvolvimento do ensaio de resistência ao fogo da parede $1(10 \mathrm{~cm})$

\begin{tabular}{c|c|c}
\hline Tempo (min) & Deslocamento $(\mathbf{m m})$ & Distância $(\mathbf{m m})$ \\
\hline 0 & 0 & 7.001 \\
5 & 11 & 7.012 \\
10 & 22 & 7.023 \\
15 & 28 & 7.029 \\
20 & 33 & 7.034 \\
25 & 36 & 7.037 \\
30 & 38 & 7.039 \\
40 & 39 & 7.040 \\
50 & 39 & 7.040 \\
60 & 39 & 7.040 \\
70 & 4 & 7.041 \\
80 & 4 & 7.041 \\
90 & 42 & 7.043 \\
100 & 43 & 7.044 \\
110 & 43 & 7.044 \\
120 & 44 & 7.045 \\
\hline
\end{tabular}

Tabela 6 - Desenvolvimento do ensaio de resistência ao fogo da parede $2(14 \mathrm{~cm})$

\begin{tabular}{c|c|c}
\hline Tempo $(\mathbf{m i n})$ & Deslocamento $(\mathbf{m m})$ & Distância $(\mathbf{m m})$ \\
\hline 0 & 0 & 7.424 \\
5 & 6 & 7.430 \\
10 & 15 & 7.439 \\
20 & 27 & 7.451 \\
30 & 40 & 7.464 \\
40 & 45 & 7.469 \\
50 & 49 & 7.473 \\
60 & 52 & 7.476 \\
70 & 56 & 7.480 \\
80 & 59 & 7.483 \\
90 & 62 & 7.486 \\
100 & 64 & 7.488 \\
110 & 67 & 7.491 \\
120 & 69 & 7.493 \\
\hline
\end{tabular}

Nas Figuras 12 e 13 são apresentadas as características gerais das paredes 1 e 2 após a realização do ensaio do choque mecânico.

$\mathrm{Na}$ análise da estabilidade não se observou o colapso. Ambas as paredes atenderam aos preceitos normativos, contudo a parede 2 , de maior espessura, embora apresente inércia maior, apresentou as maiores deformações. Guo e Shi (2011) citam que a deformação aceitável em termos de segurança estrutura é de 1/30 do maior lado da parede, o que não foi observado nos ensaios. Em termos de análise de resistência mecânica, nenhuma das amostras apresentou deformações excessivas ou qualquer tipo de comprometimento quando submetidas ao impacto das esferas metálicas.

\section{Avaliação final}

Os resultados obtidos contribuem para as opções de espessuras do sistema de vedação desse tipo apresentado pela IT08 (SÃO PAULO, 2011). No entanto, destaca-se que esses resultados divergem dos apresentados pela própria IT08:2011, a qual não permite o uso de espessuras de paredes de concreto maciço de $11,5 \mathrm{~cm}$ para tempos maiores que $60 \mathrm{~min}$, bem como da EN 1992-1-2 EUROPEAN..., 2004), a qual não permite o uso de espessuras de parede de concreto maciço de $10 \mathrm{~cm}$ para tempos maiores que $90 \mathrm{~min}$. 
Figura 12 - Aspecto final da parede $1(10 \mathrm{~cm})$ após o teste do choque mecânico

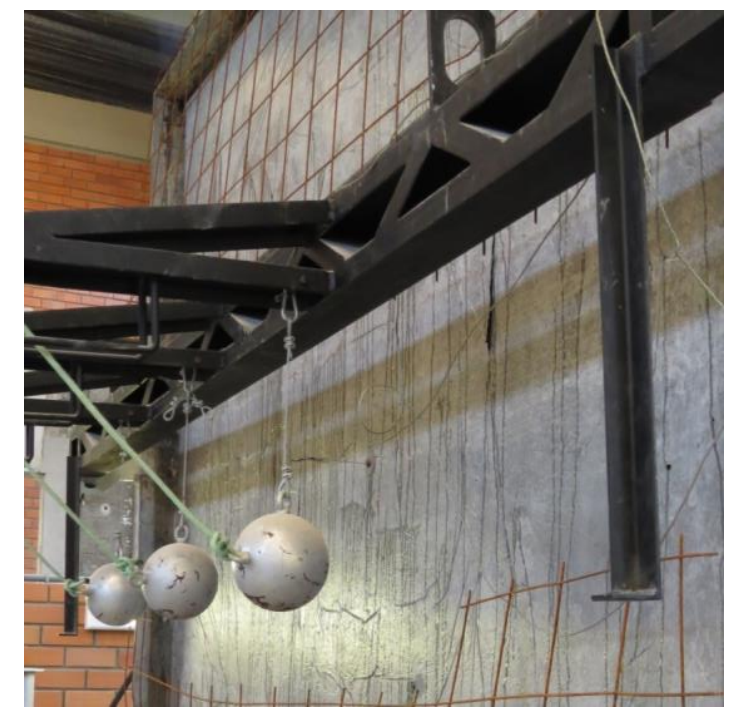

Figura 13 - Aspecto final da parede $2(14 \mathrm{~cm})$ após o teste do choque mecânico

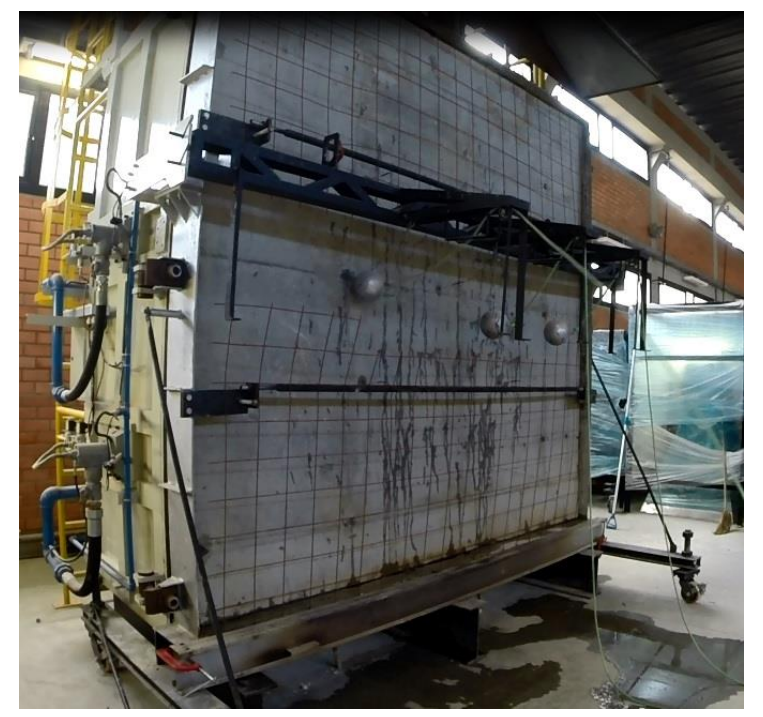

\section{Conclusão}

Neste trabalho foi efetuado o teste de duas paredes maciças em concreto armado nas dimensões de $3,15 \times 3,00 \times 0,10 \mathrm{~m}$ (parede 1) e $3,15 \times 3,00 \times 0,14 \mathrm{~m}$ (parede 2) segundo a curva de aquecimento dos gases especificados pela NBR 10636 (ABNT, 1989). Foram analisados os critérios de isolamento térmico, estanqueidade e estabilidade estrutural.

Conclui-se que as paredes 1 e 2 apresentaram resistência contra o fogo para o tempo de $120 \mathrm{~min}$, atendendo às exigências de estanqueidade, isolamento térmico e estabilidade segundo a classificação da NBR 10636 (ABNT, 1989). Com isso é possível afirmar que as paredes de vedação vertical executadas em concreto de fck $25 \mathrm{MPa}$, com o traço e as armaduras utilizados neste artigo, podem atender aos requisitos de segurança contra incêndio para as espessuras de $10 \mathrm{~cm}$ e $14 \mathrm{~cm}$, porém com a de $14 \mathrm{~cm}$ mostrando melhores resultados.

\section{Referências}

AMERICAN SOCIETY FOR TESTING AND MATERIALS. E 119: standard test methods for fire tests of building construction and materials. West Conshohocken, 2014.

ASSOCIAÇÃO BRASILEIRA DE NORMAS TÉCNICAS. NBR 10636: paredes divisórias sem função estrutural: determinação da resistência ao fogo: método de ensaio. Rio de Janeiro, 1989. 
ASSOCIAÇÃO BRASILEIRA DE NORMAS TÉCNICAS. NBR 14432: exigências de resistência ao fogo de elementos construtivos de edificações: procedimento. Rio de Janeiro, 2001a. ASSOCIAÇÃO BRASILEIRA DE NORMAS TÉCNICAS. NBR 14931: execução de estruturas de concreto: procedimento. Rio de Janeiro, 2004 ASSOCIAÇÃO BRASILEIRA DE NORMAS TÉCNICAS. NBR 15200: projeto de estruturas de concreto em situação de incêndio. Rio de Janeiro, 2012.

ASSOCIAÇÃO BRASILEIRA DE NORMAS TÉCNICAS. NBR 15575: edificações habitacionais: desempenho. Rio de Janeiro, 2013.

\section{ASSOCIAÇÃO BRASILEIRA DE NORMAS} TÉCNICAS. NBR 5628: componentes construtivos estruturais: determinação da resistência ao fogo. Rio de Janeiro, 2001b.

AUSTRALIAN STANDARD. AS 1530: methods for fire tests on building materials, componentes and structures. Sydney, 2005.

BOLINA, F.; ESTEVAM, E.; TUTIKIAN, B. Análise das Estruturas de Concreto Armado Segundo os Preceitos de Desempenho, Durabilidade e Segurança em Situação de Incêndio Conforme as Prescrições Normativas Brasileiras. In: JORNADAS DE SEGURANÇA AOS INCÊNDIOS URBANOS DE PORTUGAL, 4., Bragança, 2014. Proceedings... Bragança: Instituto Politécnico de Bragança, 2014.

BRITISH STANDARD. BS 1992-1-2: design of concrete structures: general rules: structural fire design. London, 2004b.

BRITISH STANDARD. BS 476-3: fire tests on building materials and structures: classification and method of test for external fire exposure to roofs. London, 2004a.

BUCHANAN, A.; MUNUKUTLA, V. R. Fire Resistance of Load-Bearing Reinforced Concrete Walls. Fire Safety Science 3, Borehamwood. 1991. p. 771-780.

CADORIN, J.-F. Comportment Fire Models for Structural Engineering. Tese (Doutorado em Engenharia Civil) - Escola de Engenharia, Faculdade de Ciências Aplicadas, Universidade de Liege, Liege, 2003.

\section{EUROPEAN COMMITTEE FOR}

STANDARDIZATION. EN 1992-1-2: eurocode 2: design of concrete structures: part 1.2 general rules: strcuttural fire design. Bruxelas, 2004.
FÉDÉRATION INTERNATIONALE DU

BÉTON. Fire Design of concrete Structures: structural behavior and assessment. Lausanne: CEB-FIP, 2008. Bulletin $n^{\circ} 46$.

GUO, Z.; SHI, X. Experiment and Calculation of Reinforced Concrete at Elevated Temperatures. Waltham: Elsevier, 2011.

INTERNATIONAL ORGANIZATION FOR STANDARDIZATION. ISO 834-1: fire-resistance tests: elements of building construction: part 1: general requeriments. Genebra, 1999.

JAPANESE INDUSTRIAL STANDARDS. JIS A 1304: method of fire resistance test for structural parts of buildings. Tokyo, 1994.

METHA, P. K.; MONTEIRO, P. J. M. Concreto: microestrutura, propriedades e materiais. 3. ed. São Paulo: IBRACON, 2014.

OLIVEIRA, T. A. de C. P. Fire Resistance of Composite Columns Made of Concrete Filled Circular Hollow Sections and With Restrained Termal Elongation. Tese (Doutorado em Engenharia Civil) - Escola de Engenharia, Universidade de Coimbra, Coimbra, 2013.

ROBERT, F.; COLINA, H.; DEBICKI, G. A Durabilidade do Concreto Mediante ao Fogo. In: . OLIVIER, J.-P.; VICHOT, A. (Eds.).

Durabilidade do Concreto: bases científicas para a formulação de concretos duráveis de acordo com o ambiente. IBRACON: São Paulo, 2014. p. 510557.

RIO GRANDE DO SUL. Lei complementar $n^{\circ}$ 14376, de 26 de dezembro de 2013. Estabelece normas sobre Segurança, Prevenção e Proteção contra Incêndios nas edificações e áreas de risco.

Diário Oficial do Estado do Rio Grande do Sul, Porto Alegre, 2013.

SANTOS, C. C.; RODRIGUES, J. P. Propriedades Mecânicas Residuais de Betões Correntes após Incêndio. In: CONGRESSO IBERO-LATINOAMERICANO SOBRE SEGURANÇA CONTRA INCÊNDIO, 2., Coimbra, 2013. Proceedings... Coimbra, 2013.

SÃO PAULO (Estado). Secretaria de Estado dos Negócios da Segurança Pública. Polícia Militar. Corpo de Bombeiros. Instrução Técnica n. 8: resistência ao fogo dos elementos de construção. São Paulo, 2011.

SILVA, V. P. Projeto de Estruturas de Concreto em Situação de Incêndio. São Paulo: Blucher, 2013.

WANG, Y. et al. Performance Based Fire Engineering of Structures. New York: CRC Press, 2013. 
Fabrício Longhi Bolina

ITT Performance | Universidade do Vale do Rio dos Sinos | Av. Unisinos, 950, São João Batista | São Leopoldo - RS - Brasil | CEP 93022-000 | Tel.: (51) 3590-8887 Ramal3291 | E-mail: fabriciolb@unisinos.br

\section{Gustavo Luis Prager}

ITT Performance | Universidade do Vale do Rio dos Sinos | E-mail: gprager@unisinos.br

Eduardo Rodrigues

ITT Performance | Universidade do Vale do Rio dos Sinos | E-mail: eduardoec@unisinos.br

Bernardo Fonseca Tutikian

ITT Performance | Universidade do Vale do Rio dos Sinos | Tel.: (51) 3591-1122 | E-mail: bftutikian@unisinos.br

\section{Revista Ambiente Construído}

Associação Nacional de Tecnologia do Ambiente Construído

Av. Osvaldo Aranha, $99-3^{\circ}$ andar, Centro

Porto Alegre - RS - Brasil

CEP 90035-190

Telefone: +55 (51) 3308-4084

Fax: +55 (51) 3308-4054

www.seer.ufrgs.br/ambienteconstruido

E-mail: ambienteconstruido@ufrgs.br 